"This is an Accepted Manuscript of an article published by Taylor \& Francis in Chinese Sociological Review on 18 Apr 2017 available online:

https://www.tandfonline.com/doi/full/10.1080/21620555.2017.1307689]."

Social Capital and Job Search in Urban China:

The Strength-of-Strong-Ties Hypothesis Revisited

\author{
Elena Obukhova ${ }^{1}$ \\ McGill University \\ Letian Zhang \\ Harvard University \\ (Accepted for publication in Chinese Sociological Review) \\ https://doi.org/10.1080/21620555.2017.1307689
}

Acknowledgements: We are grateful to Yasheng Huang for making the data available to us. We also thank Chinese Sociological Review editor and reviewers, participants at the Academy of Management Annual Meeting at Vancouver and in MIT's Economic Sociology Working Group for their comments and feedback. An earlier version of this paper was a finalist for the Academy of Management Careers Division Best Paper Award.

\footnotetext{
${ }^{1}$ Corresponding author at Desautels Faculty of Management, McGill University, 1001 Sherbrooke St. West, Rm 483, Montreal, QC H3A 1G5, Canada. Tel 514398 5919. E-mail address: elena.obukhova@ mcgill.ca.
} 


\title{
Social Capital and Job Search in Urban China: \\ The Strength-of-Strong-Ties Hypothesis Revisited
}

\begin{abstract}
The Strength-of-Strong-Ties Hypothesis (SSTH) suggests that because of cultural and institutional factors, Chinese job seekers benefit more from their strong social ties than weak ones. However, the methodology used to support SSTH has not been subjected to robust empirical examination. Using data from the job search of 172 Chinese college graduates, we compared findings from the commonly used direct effects methodology, which examines the effect of the strength of a tie used to find a job on income, with the more robust social capital methodology, which examines the effect of network resources. We found that compared to the latter, the former overstates the effects of strong ties on getting a high-paying job and understates the effects of weak ties. We discuss methodological and substantive implications of our results for further study of social networks in China.
\end{abstract}




\section{Introduction}

The Strength-of-Weak-Ties Hypothesis (hereafter, SWTH) states that a job seeker's weak tiesthose people the job seeker knows less well-lead to better labor-market outcomes than a job seeker's strong ties - those she knows well. Because an individual's strong ties are more likely to belong to the same social circles as that person, weak ties are more likely to offer information from different social circles (Burt 1992; Granovetter 1974/1995). Furthermore, because stronger social relationships tend to develop between those who are socially similar (McPherson 2001), a job seeker's strong ties are likely to have status equal to themselves, while their weak ties are more likely to include higher status individuals with access to valuable resources (Lin, Vaughn, and Ensel 1981; Lin 1982). Supporting these theoretical predictions, most studies of Western market economies find evidence consistent with the SWTH (see Granovetter 1995; Lin 1999; Marsden and Gorman 2001; Castilla, Lan, and Rissing 2013, for reviews).

While the SWTH is intuitively plausible and appears to be well supported by research in Western market economies, many studies have found the opposite in China (Bian 1994, 1997, 2002; Cheung and Gui 2006; Bian and Huang 2009; Lu, Ruan, and Lai 2013; Bian, Huang, and Zhang 2015). These findings have led to the development of the Strength-of-Strong-Ties Hypothesis (hereafter, SSTH), an influential line of theorizing about the effect of cultural and institutional factors on the role of social networks in labor markets in China. To start, some scholars argued that, in China, strong ties are more beneficial because Chinese culture invests strong ties with trust and obligations and leads people to mistrust weak ties (Bian and Ang 1997; see also Xiao and Tsui 2007). In addition, three institutional factors have been proposed as contributing to making strong ties particularly advantageous for job searches in China: the state 
assignment system (Bian 1997), institutional holes (Bian 2002; Bian and Huang 2009), and influence-peddling (Bian, Huang, and Zhang 2015; Tian and Lin 2016).

Despite the theoretical importance of conclusions drawn from these studies, most research on social networks in China have relied on what Mouw (2003) called the direct effects methodology, which examines the direct effects of the strength of the tie on the job seeker's labor-market outcome (e.g., income). This methodology is potentially problematic because researchers focus on the contacts that led to jobs, not the strength of the ties that did not lead to jobs (Granovetter 1995; Mouw 2003; Chen 2011; Krug 2011; Obukhova 2012). Using an analytical model, Montgomery (1992) demonstrated that focusing on the strength of the ties used to find jobs can lead to wrong conclusions about the value of weak and strong ties for job seekers (see Mouw 2003, for generalization). Instead, Montgomery advocated for what he termed the social capital methodology, which examines the relationship between labor-market outcomes and the resources available to a job seeker through both weak and strong ties (see Lin 2001, for a theoretical elaboration).

In this article, we use the job-search histories of 172 graduating university students in China to compare the effect of using the direct effects methodology with the social capital methodology to estimate the effect of strong ties on income in China. An important advantage of our research site is that it allowed us to collect detailed data necessary to conduct a cross-method comparison. We found that compared to the social capital methodology, the direct effects methodology overstates the effects of strong ties on getting a high-paying job and understates the effects of weak ties. While it is premature to generalize our results to other segments of the Chinese labor market, our results raise a possibility that the finding that the SSTH holds in China might at least in part be an artifact of using direct effect methodology. Furthermore, our findings 
suggest that whether job-seekers benefit from strong or weak ties depends on her institutional contexts (McDonald, Benton, and Warner 2012; Zhao 2013; Sharone 2014).

\section{Literature Review}

As noted earlier, the SWTH has been well established in Western market economies, while other studies found that Chinese job seekers benefitted more from strong ties than weak ones (e.g., Bian 1994, 2002; Cheung and Gui 2006; Bian and Huang 2009; Lu et al. 2013; Bian et al. 2015). In particular, Bian (1994) discovered that those who found jobs through strong ties had jobs in higher-ranked work units than those who found jobs through weak ties. Many studies corroborated these results using different samples and outcome variables; for example, Cheng and Gui (2006) reported that the strength of a tie was correlated with both income and job satisfaction; Lu et al. (2013) found that the number of strong ties was associated with higher income; and, most recently, Bian et al. (2015) showed that those who received help from strong ties were more likely to obtain a job with superior earning opportunities.

Explanations for these findings tend to emphasize a combination of cultural and institutional factors. Some researchers (e.g., Bian and Ang 1997; Cheung and Gui 2006) pointed to aspects of Chinese culture that lead people to view strong ties with trust and obligation and to mistrust weak ties. Research suggests that Chinese people tend to place heavy emphasis on family and close friendships (Bian 1997) and some scholars have argued that this cultural propensity to rely on strong ties extends to other Asian societies with Confucian heritage as well (e.g. Bian and Ikeda 2014). Consistent with this theorizing, some studies found that, in the Chinese culture, people do not benefit from networks rich in weak ties in the same way as those in Western culture do (see Xiao and Tsui 2007, for China; see Ma, Huang, and Shenkar 2011, for 
Taiwan). These arguments suggest that, regardless of changes in China's labor-market institutions, Chinese job seekers benefit more from strong ties than from weak ties.

In addition to cultural predisposition, there are three institutional factors that have been proposed as contributing to making strong ties particularly useful for job searches in China. The first is the state-assignment system that existed in China until late 1980s. Bian (1994) argued that when the state assigned people to jobs, job seekers used their contacts to influence the jobassignment process. Because going around the job-assignment process was potentially dangerous for both the job seeker and contacts trying to help them, people typically sought help from and offered help to only those whom they could trust — that is, their strong ties. Similarly, studies of other socialist economies suggested that when people used ties to engage in activities that were potentially illegal, such as obtaining scarce goods through grey channels, they often turned to strong ties (see Volker and Flap 1999, 2001, for the former GDR; see Michailova and Worm 2003, for the former USSR).

Yet, this explanation, while compelling, cannot account for why studies continued to find support for the SSTH, even after the dismantling of the state-assignment system (e.g., Bian 2002; Cheung and Gui 2006; Bian and Huang 2009; Lu et al. 2013; Bian et al. 2015). An alternative explanation proposed a second institutional factor to account for SSTH in China - the emergence of institutional holes in China's labor markets after the end of the state assignment system. Institutional holes are imperfections in formal institutions that make it difficult to transmit information, build trust, and create obligations between job seekers and employers (Bian 2002; Bian, and Huang 2009). It follows that because strong ties are more trusted and more likely to convey complex information, and they are more useful than weak ties in helping job seekers and employers to bridge institutional holes (e.g. Lu et al. 2013). These arguments suggest that as 
Chinese labor markets develop and institutional holes are filled, the advantages of strong ties will decline (Zhao 2013).

More recently, scholars have proposed that the continuing dominance of the state in the Chinese economy and the attendant importance of influence-peddling is the third factor to account for SSTH in China (e.g., Bian et al. 2015; Tian and Lin 2016). Scholars noted that even as institutional holes were being filled, strong ties retained some of their advantages. For example, Tian and Lin (2016) argued that because of the path-dependent character of market reform in China, employers, particularly in the state sector, were constrained by preexisting embeddedness in relationships with government officials. Accordingly, the probability of finding a job through strong ties in the state sector increased during the reform process. Similarly, Bian and colleagues (2015) argued that strong ties are better conduits for favoritism than weak ties, and that job seekers who can get access to influence were more likely to get positions with superior earning opportunities, including those in the state sector.

Although studies have elaborated compelling theoretical reasons to explain why the SSTH persists in China, we do not know if their empirical findings might be, in part, a methodological artifact. In particular, most research conducted in China that found support for the SSTH relied on a potentially problematic methodology (Montgomery 1992; Mouw 2003; cf. Lu et al. 2013), thus raising questions about the empirical foundations for the SSTH claims (Chen 2011). Below, we discuss shortcomings of the commonly used methodology and how a more robust alternative methodology can overcome these shortcomings. We explain our analytical strategy of testing both the SSTH and the SWTH using direct effects and social capital methodologies to evaluate whether the results of the two methods lead to the same conclusions. 


\section{Methodological Reasons to Revisit the SSTH in China}

Many studies of social networks in labor markets in China used the direct effects methodology, in which researchers asked job seekers about the method by which they had found their jobs; the researchers then compared labor-market outcomes (such as income or ownership of the work unit) between those who found jobs through weak ties or strong ties. This means that they considered only those contacts that led to jobs and ignored those that did not (Montgomery 1992; Granovetter 1995; Mouw 2003; Chen 2011; Krug 2011; Obukhova 2012). Using an analytic model, Montgomery (1992) demonstrated that, even if weak ties were more likely than strong ties to lead to job opportunities or to lead to better job opportunities, if only the association between the strength of a tie used to find a job and the labor-market outcome was examined, the researchers might reach the erroneous conclusion that strong ties are better than weak ties (see Mouw 2003, for a generalization of Montgomery's model).

The key to this counterintuitive result is that the quality of a job found reflects the quality of opportunities available to a job seeker, not the effect of a tie used to get this job. Consider one job seeker who has a network with one strong and one weak tie, and another job seeker who has only one weak tie. It might be expected that, because the first job seeker has a richer network than the second (two ties versus one), that person would have more opportunities, and therefore it would be expected that this job seeker would end up with a higher paying job than the second job seeker. ${ }^{1}$ Keep in mind, though, that the first job seeker might have found his or her job through either the strong tie or the weak one. In contrast, the second job seeker must have found his or her job through the weak tie. Thus, in this example, if the job seekers' total number of ties were not counted, it is possible to mistakenly conclude that strong ties are associated with higher wages, rather than that the first job seeker had more opportunities to begin with. The conclusion 
of this model is that a relationship between labor-market outcomes for those who found jobs through strong ties and those who found jobs through weak ties cannot be taken as indications that strong ties are more beneficial than weak ones, or vice versa.

This potential problem with the direct effects methodology led many researchers to adopt the social capital methodology (e.g., Lin et al. 1981; de Graaf and Flap 1988; Boxman et al. 1991; Barbulescu 2015; Chen and Volker 2015). Drawing on the concept of social capital, which Lin (1999, p. 468) defined as "resources that are accessible through one's direct and indirect ties," this methodology examines resources a job seeker can access through his or her network (Lin 1999; Lin and Dumin 1986). The key argument of social capital theory is that better connected people have better outcomes because they can have access to more information (Granovetter 1974/1995; Burt 1992) or because they can reach out to higher status contacts (Lin et al. 1981; Bian 1997). Accordingly, social capital theory implies that the relationship between the number of strong and weak ties available to the job seeker and the labor-market outcomes need to be examined (see Lin 1999, for review).

Although the social capital methodology offers an important advance over the direct effects methodology, it also has a shortcoming (Mouw, 2003, 2006; Chen 2011; see Manski, 1995, for a more general statement of this problem). A recent reexamination of the literature argues that much of the effect found in social capital studies might, in fact, reflect "the tendency of similar people to become friends rather than a causal effect of friend's characteristics" (Mouw 2003, p. 868). Specifically, as with most cross-sectional studies, the direct effects methodology cannot control for unobserved heterogeneity that may be correlated both with the job seeker's social network and with the outcome of the job search. For example, the association between the number of weak ties and labor-market outcomes could be spurious, because it is plausible that 
job seekers who are amicable or charismatic are likely to have both more weak ties and better labor-market outcomes.

In China, only one study employed the social capital methodology to find support for the SSTH among Shanghai residents (see Lu et al. 2013). This study, however, suffered from limitations due its cross-sectional design. As Lu et al. (2013, p. 363) acknowledged, because their study employed a cross-sectional design, they could not establish that strong ties enabled a job seeker to find higher paying work. Rather, it is possible that those who achieved higher status jobs were able to create more strong ties than those who did not achieve such jobs. This concern is particularly pronounced given that Lu and colleague's study had information on respondents' social networks at the time of their survey, yet respondents often had found jobs many years earlier. There is compelling evidence to suggest that social networks evolve to reflect one's social position (Lin and Dumin 1986).

One way to strengthen the causal claims of such studies is to examine variations in the usefulness of strong and weak ties for the same job seeker (Yakubovich 2005; see also Obukhova 2012; Obukhova and Lan 2013; Fernandez and Galperin 2014; Greenberg and Fernandez 2016). This within-individual methodology takes information on the multiple contacts that a job seeker used in the job-search process and uses individual fixed-effect models to compare the relative effectiveness of weak and strong ties. A similar solution to omitted-variable factors has been widely adopted in studies that exploit within-individual variations using panel data (e.g., Mouw 2002, 2003; McDonald, 2011).

In this study, we use both the direct effects methodology and the social capital methodology to understand how they might each shape the evaluation of the SSTH and the SWTH in China. First, we employ the direct effects methodology to examine the relationship 
between the strength of the tie used to find a job and the job seeker's income. Second, we employ the social capital methodology to examine the relationship between the job seeker's social capital and income. Last, to strengthen the claims of causality of the social capital methodology, we use individual fixed effects to see if the same job seeker was more likely to get help from a strong or weak tie. If the conclusions of the direct effects methodology differ from the social capital methodology, this indicates that method choice can influence conclusions.

\section{[Insert Table 1 Here]}

\section{Data and methods}

Our data were collected in summer 2011 at four universities in southern China. Two universities are located in Hangzhou, the capital of Zhejiang Province, and the other two are in Kunming, the capital of Yunnan Province. Zhejiang Province, which neighbors Shanghai, is one of the most rapidly developing cities in China, with a per capita GDP of over 9,000 USD. Yunnan Province, bordering Myanmar, Laos, and Vietnam, and home to many ethnic minorities, is one of the slower growing regions, with a per capita GDP of less than \$3,000 USD. These four universities vary widely in quality: one is consistently ranked as a top school in China, two are midrange schools, and the one is a low-ranked school.

The survey module on job search was included in a larger survey designed to investigate education quality, with a special focus on business and management majors. Following Yakubovich (2005), we asked students to list up to five contacts whom they could have asked for help in their job search. Thus, for each contact, students indicated (a) if they were emotionally close to the contact, and (b) the type of relationship (students were given four choices: acquaintance, professor, friend, and family member). For each contact, we asked whether the contact had provided help in job search. Elsewhere in the survey, the students were asked to 
provide information about the income of the job they found, as well as demographic information. School administrators distributed the survey to selected "classrooms": groups of 30 to 40 students who took most of their courses together.

Our sample comprised 172 students who both found jobs and provided information about their income. Because the survey was administered well before graduation, only 490 had found a job at the time of the survey. ${ }^{2}$ Out of 490 who found jobs 172 reported income. It is important to note that some nonresponses on the income question might be due to the fact that at hiring, employers give students only an income range, so the exact income is determined after completion of a probationary period. Nevertheless, to test for a potential response bias, we examined factors including gender, self-reported class rank, urban hukou status, and Chinese Communist Party (CCP) membership to see if any particular factor affected who did and did not provide income information. We did not find any statistically significant differences with respect to any of these variables.

It is important to acknowledge both the advantages and limitations of our data. Our strategic research site has enabled us to collect very detailed job search data. In contrast to midcareer workers who might intermittently look for new jobs, graduating students engage in an intense spurt of search activity over a relatively short timeframe. This means they are more likely to have more specific recall of their multiple contacts than those changing jobs midcareer, and a researcher can therefore collect detailed data. However, it is important to acknowledge that the unique aspects of our research setting, the non-random sampling process and the sample loss due to non-response can all potentially lead to biased estimates. Nevertheless, because our goal is to compare results derived from application of the two methods to the same dataset, any bias that might have resulted from these factors is relatively unlikely to affect the results of our cross- 
method comparison. For that to be the case, the bias would have to affect results of one methodology differently than the other. While this is certainly possible, we are not aware of any process that can cause this to occur in our case.

\section{Variables and Models: Direct Effects and Social Capital Tests}

To conduct the direct effects and social capital tests we used OLS regression. The dependent variable was a student's future monthly income. Income is the most commonly used measure of job-search outcomes in studies in Western market economies (see Mouw 2003, for review). This was not always the case in China. When the degree of state control of the Chinese economy was high, scholars persuasively argued that income might not be as accurate a reflection of one's social position in the planned economy as the position of one's work unit in the bureaucratic structure (e.g., Bian 1994; Walder 1995). However, as the influence of markets spread in the Chinese economy, the position of the work unit in the bureaucracy became a less important predictor of income or status (Bian and Logan 1996); thus, studies increasingly used income as a measure of labor-market success in China as well (e.g., Cheng and Gui 2013; Lu et al. 2013).

For our independent variables, we used two indicators of tie strength that captured different dimensions of this concept (see Bian 1994; Tian and Lin 2016). Our first indicator was emotional closeness, a key element of Granovetter's (1974/1995) original conception of tie strength. Marsden and Campbell (1988; see also Marsden and Campbell 2012) identified emotional closeness as the most reliable indicator of tie strength. ${ }^{3}$ Following existing studies, we also used the relationship type between the job seeker and the contact (that is, whether the contact was an acquaintance, professor, friend, or family member) as an indicator of tie strength. It is generally assumed that acquaintances are weak ties. In our analyses we considered family 
and friends as strong ties. Many researchers agree that, in China, family and friendship ties are strong, in that they carry considerable sentiment and unconditional obligation (Bian 1997;

Obukhova 2012; Lu et al. 2013). We expected that ties to professors are of intermediary strength. Using both measures of tie strength, we created independent variables for each methodology. For the direct effects methodology, we focused on how the student found a job. We created a dummy, close contact led to job, coded 1 if the student indicated that a job had been found through a contact, and that this contact was emotionally close. Similarly, we created dummy variables acquaintance led to job, professor led to job, friend led to job, and family member led to job. Because some students in our sample found their jobs through the marketplace, we also created a dummy, through market, coded 1 if the student found a job this way. For the social capital methodology, we focused on the number of contacts a student had available. We created count variables, number of close contacts and number of distant contacts, measuring the number of contacts students indicated they had available and that they were or were not emotionally close to. We also created count variables for contacts of each relationship type: number of acquaintances, number of professors, number of friends, and number of family members.

Our models included a variety of individual-level controls that previous research suggested as important in our setting (e.g., Bian 1997; Obukhova 2012). Specifically, we controlled for students' gender, self-reported membership in the CCP, and self-reported class rank. Students reported their class rank on the scale bottom 10\%, below average, average, above average, and top 10\%. We also controlled for students' urban residential registration (hukou) status. Those who have urban hukou are likely have better access to educational and other opportunities than those who have rural hukou (Wu and Treiman 2004; Chan and Buckingham 
2008). Most important for our analysis, rural hukou can limit job-search options. Finally, we controlled for students' family backgrounds using information about fathers' education, which were coded in three levels: not completing high school education or below; completion of high school education, and college education or above.

\section{Variables and Models: Within-Individual Test}

To conduct a within-individual test, we employed a linear regression with individual fixed effects. The direct effects and social capital models used the individual as a unit of analysis, while the within-individual model used a contact that a student listed as available to help. Because error terms across contacts listed by the same individual are not independent, we then created a dummy variable (or fixed effect) for each student, the coefficient of which captured the difference between the intercept for this respondent and for the sample as a whole. This student dummy captured all of the student's observed and unobserved characteristics, mitigating concerns that the association between an individual's characteristics and labor-market outcomes was due to unobserved variables. As a result, we interpreted the remaining coefficients as the effects of tie strength on labor-market outcomes for the same individual.

Because a contact was the unit of analysis for within-individual models, we constructed new dependent and independent variables. We did not use income as a dependent variable for within-individual models because it was not possible to collect information on salaries for all the jobs a student applied for through each contact. This is a common limitation for studies that use the within-individual methodology. To date, only one study (Greenberg and Fernandez 2016) was able to obtain information on compensation for multiple jobs. Instead, for each contact, we created the dummy variable provided help and coded it 1 if the contact provided help. The 
independent variables in our analysis were the characteristics of each contact. Specifically, for each contact, we created five dummy variables: close contact, acquaintance, professor, friend, and family member.

\section{Results}

Before we turn to the results of direct effects and social capital tests, we discuss some notable descriptive findings. Table 2 Rows 2-7 present descriptive statistics for the independent variables used in the direct effects models. In our sample, $55 \%$ of students found their jobs through close contacts. Turning to the type of relationship, 5\% found their jobs through acquaintances, $9 \%$

through professors, $25 \%$ through friends, and $29 \%$ through family members. Also, note that $33 \%$ of the students found their jobs through the market methods. Table 2 Rows 8-13 present descriptive statistics for the independent variables used in the social capital models. On average, students listed 1.35 close contacts, 0.22 distant contacts, 0.15 acquaintances, 0.26 professors, 0.58 friends, and 0.58 family members.

We also found that $47 \%$ of our sample was male and $49 \%$ were CCP members. The average self-reported class rank was 2.45 (that is, between above average and average); the modal answer was average. More than two thirds of our sample was comprised of urban residents. In most cases, fathers' education was below high school. Also, bivariate correlations indicated that students who were CCP members tended to have a higher class rank than did nonCCP members. This is probably due to the fact that academic performance is a criterion in the selection of CCP members. Also, note that male students were less likely to be CCP members than female students and, on average, had lower self-reported class ranks. Nevertheless, male students tend to earn a higher income, a fact that partially explains the negative association 
between class rank and income in our sample. CCP members also reported higher salaries than non-CCP members.

[Insert Table 2 About Here]

\section{Direct Effects Test}

To conduct a test of the SSTH and SWTH using the direct effects methodology (H1a and H2a in Table 1) we employed OLS regression to examine whether the strength of the tie that led to the job was associated with income (see Table 3). The results of models using closeness-but not relationship type — as an indicator of tie strength provided weak support for SSTH.

Specifically, consistent with H1a, Model 1 indicates that students earn more when they find a job through a close tie than when they find one through a distant tie, although this result is only marginally significant $(\beta=0.89, p<0.10)$. Using the relationship type as our indicator of tie strength, Model 2 finds no support for SSTH or SWTH. It shows no significant relationship between income and finding a job through family or friends. ${ }^{4}$ Overall, using the direct effects methodology, we found some empirical evidence supporting the SSTH but not the SWTH.

[Insert Table 3 About Here]

\section{Social Capital Test}

To conduct a test of the SSTH and SWTH using the social capital methodology (H1b and $\mathrm{H} 2 \mathrm{~b}$ in Table 1) we employed OLS regression to examine whether students' social capital was associated with income (Table 4). The results of models using relationship type - but not 
closeness - as an indicator of tie strength are inconsistent with SSTH. Specifically, Model 1 indicates no relationship between the number of close ties and income. In Model 2, we found that the number of family members was not associated with income. Also, contrary to H1b, the number of friends was associated with lower income, but this effect was only marginally significant $(\beta=0.54, p<0.10)$. We also found support for SWTH. Specifically, consistent with $\mathrm{H} 2 \mathrm{~b}$, we found that having more acquaintances was associated with higher income $(\beta=1.03, p<$ 0.01). Overall, using the social capital methodology, we found some evidence contrary to the SSTH and some evidence supporting the SWTH.

[Insert Table 4 About Here]

\section{Within-Individual Test}

To conduct a within-individual test of the SSTH and SWTH (H1c and H2c in Table 1), we used linear probability models to explore the relationship between tie strength and the likelihood of getting help from the strong and weak ties (see Table 5). Our results provided no support for SSTH. Specifically, contacts emotionally close to the job seeker were less likely to help than those who were not close (Model 1a). Contrary to H1c, Model 1b indicates that friends are less likely to give help than acquaintances $(\beta=-0.28, p<0.05) .{ }^{5}$ The coefficient for family members is also negative, though not statistically significant. In the model that has controls for both closeness and relationship type, no coefficient was significant. Overall, the results of the withinindividual test do not provide support for the SSTH. 


\section{[Insert Table 5 About Here]}

Because these within-individual models only include 266 contacts listed by the 172 students, one potential concern was that the sample size was insufficient to accurately estimate within-individual models due to a loss of cases lacking within-individual variation. Specifically, the model can only make an estimate based on those who had variations on the independent variable (that is, they had at least one close contact and at least one distant contact) and variations on the dependent variable (that is, they received help from at least one, but not from all, of their contacts). To mitigate a potential concern that this sample size was insufficient for estimating within-individual models, we also replicated our analyses with an expanded sample of 599 students who provided information on 1,009 contacts but who did not necessarily find a job (Models 2a, 2b, and 2c). The larger sample provided an additional robustness check on whether our results were simply due to insufficient sample size.

In this expanded sample, we found evidence contrary to SSTH but some support for SSWH. Contrary to H1c, we found that emotionally close contacts were no more likely than distant ones to provide help (Model 2a). Unlike in Model 1a, the coefficient was positive, but it was very close to 0 . Consistent with $\mathrm{H} 2 \mathrm{c}$, Model $2 \mathrm{~b}$ indicates that acquaintances were more likely to provide help than professors, friends, and family members. Specifically, we found that compared to acquaintances, a job seeker was $12 \%$ less likely to receive help from a professor, $13 \%$ less likely from a friend, and $9 \%$ less likely from a family member. Note that these coefficients were also negative in Model 1b, but only friend was statistically significant. In Model 2c we included both indicators of tie strength, and the results remained substantively similar. In sum, analyses using an expanded sample confirmed the findings from the analysis of the original sample reported and provided support for the SWTH, not the SSTH. 
In sum, our results indicate that the methodology used had substantive effects on our findings; that is, the use of the direct effects methodology might have biased results toward support for the SSTH. Specifically, we found support for the SSTH using the direct effects methodology (H1a), and support for the SWTH using the social capital methodology (H2b), indicating that the direct effects methodology biases resulted toward finding support for the SSTH. We also found support for the SWTH using within-individual methodology.

\section{Additional Analyses}

To rule out the possibility that tie strength is a proxy for a contact's status, we replicated all our models with a control for contact status. Job seekers benefit more from high-status contacts (Lin 1982, 2000; Lin et al. 1981; Bian 1994). It is possible that the relationship between tie strength and labor-market outcomes might be spurious, because it is likely that strong ties are equal in status to the job seeker, but that some weak ties are of higher status. In the survey, participants indicated whether each contact was a manager or a cadre - a person employed in government or in an administrative position in the state sector. Using this information, for each student, we constructed a dummy variable high-status tie led to job (for the direct effects methodology) and a count variable number of high-status ties (for the social capital methodology). Also, for the within-individual test, we constructed a dummy variable high status for each contact. We replicated all of our analyses with these controls, and the results of substantive interest remained largely the same.

\section{Discussion and Implications}


Extensive scholarship has elaborated theoretical reasons to expect that the SSTH holds in China, yet there are reasons to reexamine the empirical foundations of these claims. We thus tested the SSTH using both the conventional direct effects methodology and the more methodologically rigorous social capital methodology. The results of the direct effects model using emotional closeness - but not relationship type - provided weak evidence supporting the SSTH. In contrast, the results of the social capital model using relationships type- but not emotional closenessprovided evidence contrary to SSTH. Furthermore, we employed the within-individual test to demonstrate that a job seeker with both a strong tie and a weak tie was more likely to receive help from the weak tie. Taken together, the pattern of results suggested that, in China, the use of the direct effects methodology may overstate the importance of strong ties and understate that of weak ties.

Our study has limitations. First, we cannot explain the differences in results between two dimensions of tie strength. Nevertheless, these results were not surprising, because prior research indicated that different dimensions of ties strength might be only loosely correlated (e.g., Marsden and Campbell 1988, 2012). Second, our study did not examine which specific resources either weak or strong ties transmitted in our context. Recent research suggested that strong and weak ties might transmit different types of resources; that is, strong ties are more likely to transmit influence and weak ties — information (Bian et al. 2015; Tian and Lin 2016). Given our research design, we were not able to investigate why students benefited more from weak ties than strong ties, leaving this question to be investigated by future research.

Also, although studying graduating university students allowed us to collect the detailed data necessary to evaluate both methodologies, we do not claim generalizability. We focused on a segment of the labor market that has few institutional holes. Many students can bypass 
networks altogether to find desirable jobs through on-campus recruiting (e.g., Obukhova 2012). Our study, then, does not rule out the possibility that in segments in which labor-market institutions are less developed, job seekers might benefit more from strong ties than from weak ones. In fact, a recent study by Lu et al. (2013) that used the social capital methodology found a positive relationship between the numbers of strong ties a job seeker had and income, even in a city with labor markets as developed as Shanghai. Taken together, both Lu et al.'s (2013) and our research results call for future research that combines nationally representative samples and the use of robust methodologies to explore these issues further.

Our results have important implications for continued research on the SSTH in China and elsewhere. First, our study underscores the need for future research on social networks in China to abandon the use of the direct effects methodology in favor of more robust methods. Corroborating the results of Montgomery's analytic model (1992), our study provides important empirical evidence that the direct effects methodology can bias results toward finding support for the SSTH. This raises the possibility that existing empirical studies of the SSTH overstate the benefits of strong ties and understate the benefits of weak ones for Chinese job seekers. Because our study raises important methodological doubts about results of prior studies that relied on this methodology, it is critical for future research to re-examine the SSTH in China using more robust methods.

Our study also has important implications for our understanding of the role of culture and institutions in job search in China and elsewhere. First, it raises questions about culturalist explanations for the SSTH in China (e.g., Bian and Ikeda 2014). Consistent with evidence from recent research that suggested that as labor markets develop, the use of strong ties in job search is declining in China (e.g., Huang 2008; Obukhova 2012; Zhao 2013), our results also indicate that, 
in some contexts, Chinese job seekers do not benefit from strong ties. These results echo other recent research that found that benefits of networking strategies in collectivist cultures depend on their organizational context (e.g., Xiao and Tsui 2007; Merluzzi 2013). Taken together, these results suggest that culturalist explanations for the SSTH in China overstate the effect of cultural predispositions and that the "tool kit" (Swidler 1986) of Chinese culture contains a variety of practices that individuals can draw from in response to particular situations (see also Chang 2011).

Furthermore, consistent with institutionalist perspectives on social networks in job search (McDonald et al. 2012; Sharone 2014), our results provide support to institutional explanations of the SSTH in China, and in particular those institutionalist explanations that emphasize the advantages of strong ties in labor markets with institutional holes (e.g. Bian 2002; Zhao 2013). Consistent with this perspective's predictions, we found that in university students' job searches, in which institutional holes were minimal, students did not need to rely on strong ties to find a job. It is also worth noting that the results of interprovincial comparison offer suggestive evidence further supporting this explanation. Specifically, we found some evidence that in the more developed Zhejiang Province, weak ties were more beneficial than strong ties, and the difference between weak and strong ties was less pronounced in the less developed Yunnan Province. In sum, our results highlight the need for future research to focus more attention on institutional factors that shape the use of networks in job search in China and elsewhere. 


\section{References}

Barbulescu, Roxana. 2015. "The Strength of Many Kinds of Ties: Unpacking the Role of Social Contacts across Stages of the Job Search Process." Organization Science 24 (3): 737-756.

Bian, Yanjie. 1994. "Guanxi and the Allocation of Jobs in Urban China." China Quarterly 140: 971-99.

—. 1997. "Bringing Strong Ties Back in: Indirect Ties, Network Bridges, and Job Searches in China." American Sociological Review 62(3): 366-85.

—. 2002. "Institutional Holes and Job Mobility Processes: Guanxi Mechanisms in China's Emergent Labor Market.” Pp. 117-35 in Social Connections in China: Institutions, Culture, and the Changing Nature of Guanxi, edited by T. Gold, D. Guthrie, and D. Wank. New York: Cambridge University Press.

Bian, Yanjie., and Soon Ang. 1997. "Guanxi Networks and Job Mobility in China and Singapore." Social Forces 75(3): 981-1006.

Bian, Yanjie., and Xianbi Huang. 2009. "Network Resources and Job Mobility in China's Transitional Economy.” Pp. 255-282 in Research in Sociology of Work, edited by L. Keister, Greenwich, CT: Emerald.

Bian, Yanjie. and Ken'ichi Ikeda. 2014. "East Asian Social Networks.” Pp. 1-12 in The Encyclopedia of Social Network Analysis and Mining, co-edited by Alhajj R. \& Rokne, J. Springer.

Bian, Yanjie., \& Logan, John R. 1996. "Market Transition and the Persistence of Power: The Changing Stratification System in Urban China." American Sociological Review 61(5): 739-58.

Bian, Yanjie., Xianbi Huang. and Lei Zhang. 2015. "Information and Favoritism: The Network Effect on Wage Income in China." Social Networks 40: 129-138.

Boxman, Ed. AW., Paul M. De Graaf, and Hendrik D. Flap. 1991. "The Impact of Social and Human Capital on the Income Attainment of Dutch Managers." Social Networks 13(1): $51-73$.

Burt, Ron. S. 1992. Structural Holes. Cambridge, MA: Harvard University Press.

Castilla, Emilio. J., George J. Lan, and Ben A. Rissing. 2013. "Social Networks and Employment: Mechanisms (part 1).”Sociology Compass 7: 999-1012.

Chan, Kam Wing., and Will Buckingham. 2008. "Is China Abolishing the Hukou System?" China Quarterly 195: 582-606.

Chang, Kuang-chi. 2011. "A Path to Understanding Guanxi in China's Transitional Economy: Variations on Network Behavior." Sociological Theory 29(4): 315-339.

Chen, Yunsong, and Beate Volker. 2016. "Social Capital and Homophily Both Matter for Labor Market Outcomes-Evidence from Replication and Extension." Social Networks 45: 18-31.

Chen, Yunsong. 2011. "The Causal Effect of Social Capital in the Labor Market: Identification Challenges and Strategies." Chinese Sociological Review 44(2): 76-100.

Cheung, Chau-kiu, and Yong Gui. 2006. "Job Referral in China: The Advantages of Strong Ties." Human Relations 59(6): 847-872.

De Graaf, Nan Dirk, and Hendrik Derk Flap. 1988. "“With a Little Help from My Friends": Social Resources as an Explanation of Occupational Status and Income in West Germany, The Netherlands, and the United States.” Social Forces 67(2): 452-472. 
Fernandez, Roberto M., and Roman V. Galperin. 2014. "The Causal Status of Social Capital in Labor Markets.” Pp 445-462 in Contemporary Perspectives on Organizational Social Networks. Emerald Group Publishing Limited.

Granovetter, Mark. 1974 /1995. Getting a Job: A Study of Contacts and Careers, 2nd ed. Chicago: University of Chicago Press.

—. 1995. "Introduction." In Getting a Job: A Study of Contacts and Careers, 2nd ed. Chicago: University of Chicago Press.

Greenberg, Jason, and Roberto M. Fernandez. 2016. "The Strength of Weak Ties in MBA Job Search: A Within-Person Test." Sociological Science 3: 296-316

Holzer, Harry. 1987. "Informal Job Search and Black Youth Unemployment." American Economic Review 6(1): 446-452.

Huang, Xianbi. 2008. “Guanxi Networks and Job Searches in China's Emerging Labour Market: A Qualitative Investigation.” Work, Employment \& Society 22(3): 467-484.

Krug, Gerhard. 2011. "(When) Is Job-finding via Personal Contacts a Meaningful Concept for Social Network Analysis? A Comment to Chua (2011)." Social Networks 34: 527-533.

Lin, Nan. 1982. "Social Resources and Instrumental Action." Pp. 131-45 in Social Structure and Network Analysis, edited by Marsden, P. V. \& Lin, N. Beverly Hills, CA: Sage.

—. 1999. "Social Networks and Status Attainment." Annual Review of Sociology 23: 467-87.

- 2001. Social Capital: A Theory of Social Structure and Action. New York: Cambridge University Press.

Lin, Nan, and Mary Dumin, 1986. “Access to Occupations through Social Ties.” Social Networks 8: 365-385.

Lin, Nan, John C. Vaughn, and Walter M. Ensel. 1981. "Social Resources and Occupational Status Attainment." Social Forces 59(4): 1163-1181.

Lu, Yao, Ruan, Danching, and Gina Lai. 2013. "Social capital and economic integration of migrants in urban China." Social Networks 35: 357-369.

Ma, Rong, Yen-Chih Huang, and Oded Shenkar. 2011. "Social Networks and Opportunity Recognition: A Cultural Comparison between Taiwan and the United States." Strategic Management Journal 32(11): 1183-1205.

Manski, Charles F. 1995. Identification Problems in the Social Sciences. Cambridge, MA: Harvard University Press.

Marsden, Peter V., and Karen E. Campbell. 1984. "Measuring Tie Strength.” Social Forces 63: 482-501.

—. 2012. "Reflections on Conceptualizing and Measuring Tie Strength." Social Forces 91(1): 17-23.

Marsden, Peter V., and Elizabeth H. Gorman. 2001. "Social Networks, Job Changes, and Recruitment." Pp. 467-502 in Sourcebook of Labor Markets: Evolving Structures and Processes, edited by I. Berg, and A. L. Kalleberg, New York: Kluwer Academic/Plenum.

McDonald, Steve. 2011. "What You Know or Who You Know? Occupation-specific Work Experience and Job Matching through Social Networks." Social Science Research 40(6): 1664-75.

McDonald, Steve, Richard A. Benton, and David F. Warner. 2012. "Dual Embeddedness: Informal Job Matching and Labor Market Institutions in the United States and Germany." Social Forces 91.1: 75-97.

McPherson, Miller, Lynn Smith-Lovin, and James M. Cook. 2001. "Birds of a Feather: Homophily in Social Networks." Annual review of sociology 27(1): 415-444. 
Merluzzi, Jennifer. 2013. "Social Capital in Asia: Investigating Returns to Brokerage in Collectivistic National Cultures.” Social Science Research 42(3): 882-892.

Michailova, Snejina, and Verner Worm. 2003. "Personal Networking in Russia and China: Blat and Guanxi." European Management Journal 21(4): 509-519.

Montgomery, J. D. 1992. "Job Search and Network Composition: Implications of the Strengthof-Weak-Ties Hypothesis." American Sociological Review 57(5): 586-596.

Mouw, Ted. 2002. "Racial Differences in the Effects of Job Contacts: Conflicting Evidence from Cross-Sectional and Longitudinal Data." Social Science Research 31(4): 511-38.

_. 2003. "Social Capital and Finding a Job: Do Contacts Matter?" American Sociological Review 68(6): 868-98.

—. 2006. "Estimating the Causal Effect of Social Capital: A Review of Recent Research." Annual Review of Sociology 32(1):79-102.

Obukhova, Elena. 2012. "Motivation vs. Relevance: Using Strong Ties to Find a Job in China." Social Science Research 41(3): 470-480.

Obukhova, Elena, and George Lan. 2013. "Do Job-seekers Benefit from Contacts? A Direct Test with Contemporaneous Searches." Management Science 59(10): 2204-2216.

Sharone, Ofer. 2014. "Social Capital Activation and Job Searching: Embedding the Use of Weak Ties in the American Institutional Context." Work and Occupations, 41: 409-439.

Swidler, Ann. 1986. "Culture in Action: Symbols and Strategies." American Sociological Review 51(2): 273-286.

Tian, Felicia F., and Nan Lin. 2016. "Weak Ties, Strong Ties, and Job Mobility in Urban China: 1978-2008." Social Networks 44: 117-129.

Völker, Beate, and Henk Flap. 1999. "Getting Ahead in the GDR: Social Capital and Status Attainment under Communism." Acta sociologica 42(1): 17-34

—. 2001. "Weak Ties as a Liability: The Case of East Germany." Rationality and society, 13(4): 397-428.

Walder, Andrew. G. 1995. "Career Mobility and the Communist Political Order." American Sociological Review, 60(3), 309-28.

Wu, Xiaogang, and Donald J. Treiman. 2004. "The Household Registration System and Social Stratification in China: 1955-1996." Demography 41(2): 363-384.

Xiao, Zhixing, and Anne S. Tsui. 2007. "When Brokers May Not Work: The Cultural Contingency of Social Capital in Chinese High-Tech Firms." Administrative Science Quarterly 52(1): 1-31.

Yakubovich, Valery. 2005. "Weak Ties, Information, and Influence: How Workers Find Jobs in a Local Russian Labor Market.” American Sociological Review 70(3): 408-421.

Zhao, Wei. 2013. "Social Networks, Job Search and Income Disparity in a Transitional Economy: An Institutional Embeddedness Argument." Pp. 103-32 in Research in the sociology of work, vol. 24, Networks, work and inequality, edited by S. McDonald, Bingley, UK: Emerald. 
Table 1. Summary of the SSTH and the SWTH Tests Using Alternative Methodologies.

\begin{tabular}{|l|l|l|}
\hline Tests & SSTH & SWTH \\
\hline Direct effects methodology & $\begin{array}{l}\text { H1a: Job seekers who find a } \\
\text { job through a strong tie have } \\
\text { higher income than those who } \\
\text { find a job through a weak tie. }\end{array}$ & $\begin{array}{l}\text { H2a: Job seekers who find a } \\
\text { job through a weak tie have } \\
\text { higher income than those who } \\
\text { find a job through a strong } \\
\text { tie. }\end{array}$ \\
\hline Social resource methodology & $\begin{array}{l}\text { H1b: Job seekers who have } \\
\text { more strong ties have higher } \\
\text { income than those who have } \\
\text { fewer strong ties. }\end{array}$ & $\begin{array}{l}\text { H2b: Job seekers who have } \\
\text { more weak ties have higher } \\
\text { income than those who have } \\
\text { fewer weak ties. }\end{array}$ \\
\hline $\begin{array}{l}\text { Within-individual } \\
\text { methodology }\end{array}$ & $\begin{array}{l}\text { H1c: Job seekers who use } \\
\text { both a strong and a weak tie } \\
\text { in job search are more likely } \\
\text { to get help from a strong tie } \\
\text { than a weak tie. }\end{array}$ & $\begin{array}{l}\text { H2c: Job seekers who use } \\
\text { both a strong and a weak tie } \\
\text { in job search are more likely } \\
\text { to get help from a weak tie } \\
\text { than a strong tie. }\end{array}$ \\
\hline
\end{tabular}


Table 2. Descriptive Statistics for Variables Used for SSTH Test Using Direct Effects Methodology

\begin{tabular}{|c|c|c|c|}
\hline & & Mean & St. dev. \\
\hline \multirow[t]{2}{*}{ (1) } & Income & 4.994 & 0.262 \\
\hline & Method of finding a job & & \\
\hline (2) & Close contact led to job & 0.551 & - \\
\hline (3) & Acquaintance led to job & 0.052 & - \\
\hline (4) & Professor led to job & 0.093 & - \\
\hline$(5)$ & Friend led to job & 0.248 & - \\
\hline (6) & Family member led to job & 0.287 & - \\
\hline \multirow[t]{2}{*}{ (7) } & Found job through market & 0.332 & - \\
\hline & Social capital & & \\
\hline$(8)$ & Number of close contacts & 1.351 & 0.882 \\
\hline (9) & Number of distant contacts & 0.219 & 0.471 \\
\hline$(10)$ & Number of acquaintance & 0.145 & 0.384 \\
\hline$(11)$ & Number of professors & 0.246 & 0.501 \\
\hline$(12)$ & Number of friends & 0.582 & 0.578 \\
\hline \multirow[t]{2}{*}{ (13) } & Number of family members & 0.580 & 0.557 \\
\hline & Student characteristics & & \\
\hline$(14)$ & Male & 0.470 & - \\
\hline$(15)$ & CCP member & 0.491 & - \\
\hline$(16)$ & Urban resident & 0.692 & - \\
\hline$(17)$ & Class rank & 2.452 & 0.991 \\
\hline (182) & Father education & 0.561 & 0.738 \\
\hline
\end{tabular}


Table 3. SSTH Test Using Direct Effects Methodology: OLS Models of the Effect of JobFinding Method on Monthly Income

Close contact led to job

Acquaintance led to job is reference category

Professor led to job

Friend led to job

Family member led to job

Found job through market

Class rank

Party member

Male

Urban resident

Father Education

Constant

\section{Model 1}

$0.894+$

$(0.505)$

Model 2

$-1.044$

(0.836)

$-1.191$

(0.754)

$-1.081$

(0.757)

0.406

(1.591)

$-0.580$

0.285

(1.755)

(0.207)

0.288

$0.691+$

(0.209)

(0.376)

$1.058 * *$

(0.360)

$0.748+$

(0.379)

$1.058 * *$

$-0.073$

(0.389)

(0.369)

$-0.049$

0.200

(0.396)

(0.244)

$2.575 * *$

(0.721)

0.255

(0.246)

4.326**

(0.914)

172

172

0.100
0.096

R-squared

Notes: Unit of analysis is a student. All contact variables refer to the method through which the student found a job. Standard errors in parentheses; ** $\mathrm{p}<0.01, * \mathrm{p}<0.05,+\mathrm{p}<0.10$. 
Table 4. SSTH Test Using Social Capital Methodology: OLS Models of the Effect of Social Capital on Monthly Income

\begin{tabular}{lc}
\hline & Model 1 \\
\hline Number of close contacts & 0.035 \\
& $(0.198)$ \\
Number of distant contacts & -0.372 \\
& $(0.371)$
\end{tabular}

Number of acquaintances

$1.032 *$

Number of professors

$(0.484)$

$-0.497$

$(0.368)$

Number of friends

$-0.542+$

(0.321)

Number of family members

$-0.102$

(0.323)

Class rank

0.275

0.271

$(0.21)$

$(0.210)$

Party member

$0.731+$

$0.798 *$

(0.382)

Male

$1.08 * *$

(0.381)

$(0.36)$

$1.149 * *$

Urban resident

$-0.079$

(0.347)

(0.402)

$-0.013$

0.196

(0.388)

Father education

(0.261)

0.119

$3.391 * *$

(0.258)

Constant

(0.680)

$3.640 * *$

(0.687)

Observations

172

172

R-squared

0.087

0.118

Notes: Unit of analysis is a student. All contact variables refer to the number of contacts a student listed as available for help in her job search. Standard errors in parentheses; ** $\mathrm{p}<0.01, * \mathrm{p}<0.05,+\mathrm{p}<0.10$. 
Table 5. SSTH Test Using Within-Individual Methodology: The Effect of Contact's Characteristics on Getting Help in Job Search

\begin{tabular}{|c|c|c|c|c|c|c|}
\hline & \multicolumn{3}{|c|}{ Students with income data } & \multicolumn{3}{|c|}{ Students with contact data } \\
\hline & $\begin{array}{c}\text { Model } \\
\text { 1a }\end{array}$ & $\begin{array}{c}\text { Model } \\
1 \mathrm{~b}\end{array}$ & $\begin{array}{l}\text { Model } \\
\text { 1c }\end{array}$ & $\begin{array}{l}\text { Model } \\
2 \mathrm{a}\end{array}$ & $\begin{array}{c}\text { Model } \\
2 \mathrm{~b}\end{array}$ & $\begin{array}{l}\text { Model } \\
\text { 2c }\end{array}$ \\
\hline \multirow[t]{2}{*}{ Close contact } & $-0.162+$ & & -0.129 & 0.024 & & 0.040 \\
\hline & $(0.092)$ & & (0.099) & $(0.039)$ & & $(0.039)$ \\
\hline \multicolumn{7}{|c|}{$\begin{array}{l}\text { Acquaintance is the } \\
\text { reference category }\end{array}$} \\
\hline \multirow[t]{2}{*}{ Professor } & & -0.046 & -0.021 & & $-0.116^{*}$ & $-0.122 *$ \\
\hline & & $(0.112)$ & $(0.113)$ & & $(0.047)$ & $(0.047)$ \\
\hline \multirow[t]{3}{*}{ Friend } & & $-0.228 *$ & -0.178 & & $-0.126^{* *}$ & - \\
\hline & & & & & & $0.134 * *$ \\
\hline & & $(0.101)$ & $(0.108)$ & & $(0.043)$ & $(0.044)$ \\
\hline \multirow[t]{2}{*}{ Family member } & & -0.071 & -0.016 & & $-0.087 *$ & $-0.098 *$ \\
\hline & & $(0.099)$ & $(0.107)$ & & $(0.044)$ & $(0.046)$ \\
\hline \multirow[t]{2}{*}{ Constant } & $0.936 * *$ & $0.917 * *$ & $0.984 * *$ & $0.842 * *$ & $0.962 * *$ & $0.936 * *$ \\
\hline & $(0.081)$ & $(0.087)$ & $(0.101)$ & $(0.034)$ & $(0.039)$ & $(0.046)$ \\
\hline Obs. (contacts) & 266 & 266 & 266 & 1,009 & 1,009 & 1,009 \\
\hline Students & 172 & 172 & 172 & 599 & 599 & 599 \\
\hline R-squared & 0.033 & 0.082 & 0.099 & 0.001 & 0.023 & 0.025 \\
\hline
\end{tabular}

Notes: Unit of analysis is a contact. All contact variables refer to the characteristics of the contact a student listed as available for help. Standard errors in parentheses; ${ }^{* *} \mathrm{p}<0.01,{ }^{*} \mathrm{p}<0.05,+\mathrm{p}<0.10$. 
${ }^{1}$ In standard job-search models that used in economics (e.g., Holzer 1987), this means that the first job seeker has a higher reservation wage, that is, a minimum wage at which he or she accepts a job opportunity versus a second job seeker.

${ }^{2}$ We found that students of lower class rank were more likely to have found a job. This means that we should not use finding a job as an outcome variable because a longer search might indicate difficulties in finding a job or a high confidence in finding a better job after graduating or going to graduate school.

${ }^{3}$ It is important to note that our measure of emotional closeness was dichotomous, while most researchers use a measure with four categories.

${ }^{4} \mathrm{We}$ also attempted to examine models with both measures of tie strength. However, VIF analysis results indicated unacceptably high levels of multicollinearity between our different tie strength measures.

${ }^{5}$ We attribute this finding to the fact that most of the students' friends are likely to be other students and, as a result, might be competing for the same jobs. 